$06.4 ; 12.1$

\title{
Радиоизлучение, создаваемое электрическим пробоем пленки полипропилена
}

\author{
(c) В.А. Пахотин ${ }^{1}$, Н.Т. Сударь ${ }^{2}$ \\ ${ }^{1}$ Физико-технический институт им. А.Ф. Иоффре РАН, Санкт-Петербург, Россия \\ ${ }^{2}$ Санкт-Петербургский политехнический университет Петра Великого, Санкт-Петербург, Россия \\ E-mail: v.pakhotin@mail.ioffe.ru
}

Поступило в Редакцию 19 июня 2020г.

В окончательной редакции 3 августа 2020г.

Принято к публикации 5 августа 2020г.

При электрическом пробое тонкой пленки полипропилена обнаружено излучение радиоимпульса длительностью около $400 \mathrm{~ns}$. Спектр радиоимпульса состоит из трех основных частот. Обоснована связь величины сопротивления канала пробоя с наблюдаемым спектром излучения.

Ключевые слова: электрический пробой, радиоизлучение, полипропилен.

DOI: 10.21883/PJTF.2020.22.50306.18428

Завершающей стадией электрического разрушения полимерных диэлектрических пленок является их электрический пробой. При пробое в локальной области пленки возникает проводящий канал, сквозь который могут протекать токи большой плотности. Ранее было установлено, что кратковременный фронт импульса истинного тока пробоя инициирует в измерительной электрической цепи затухающие электрические колебания $[1,2]$. Показано, что данные о частоте колебаний и времени их затухания могут быть использованы для определения сопротивления проводящего канала и оценки скорости его изменения [2]. Импульс тока электрического пробоя полимерных пленок и колебания тока в измерительной цепи должны создавать излучение в радиодиапазоне, параметры которого также могли бы быть использованы для исследования пробоя полимерной пленки. Здесь следует отметить, что известно и широко обсуждается широкоплосное излучение радиоволн при возникновении электрических разрядов [3-6], в том числе частичных разрядов в диэлектриках. Публикации, в которых рассматривались бы вопросы излучения радиоволн при пробое полимерных диэлектриков, отсутствуют. Поэтому целью настоящей работы является установление факта излучения радиоимпульса при электрическом пробое полимерной пленки, а также выяснение его параметров.

На рис. 1, $а$ представлена схема измерений. Объектом нашего исследования являлась двухосно ориентированная пленка полипропилена (РP) толщиной $4 \mu \mathrm{m}$, на которую с одной стороны термическим напылением в вакууме наносился слой алюминия толщиной $10-20 \mathrm{~nm}$. Пленка зажималась между двух латунных колец, внутренний диаметр которых равнялся $30 \mathrm{~mm}$, так что пленка заполняла все пространство внутри кольца. Кольца имели прижимной электрический контакт со слоем $\mathrm{Al}$. Слой $\mathrm{Al}$ являлся нижним электродом. В качестве второго (верхнего) электрода использовался стальной шар диаметром $4 \mathrm{~mm}$, который был завальцован в медную трубку. Шаровой электрод имел отрицательный потенциал и располагался примерно в центре латунного кольца. Электроды с образцом (измерительная ячейка) были частью установки, имеющей форму квадратной рамки с длиной плеча $l_{o}=40 \mathrm{~mm}$. Рамка была изготовлена из медного провода диаметром $2 a=5 \mathrm{~mm}$ и соединялась с шаровым электродом посредством медной

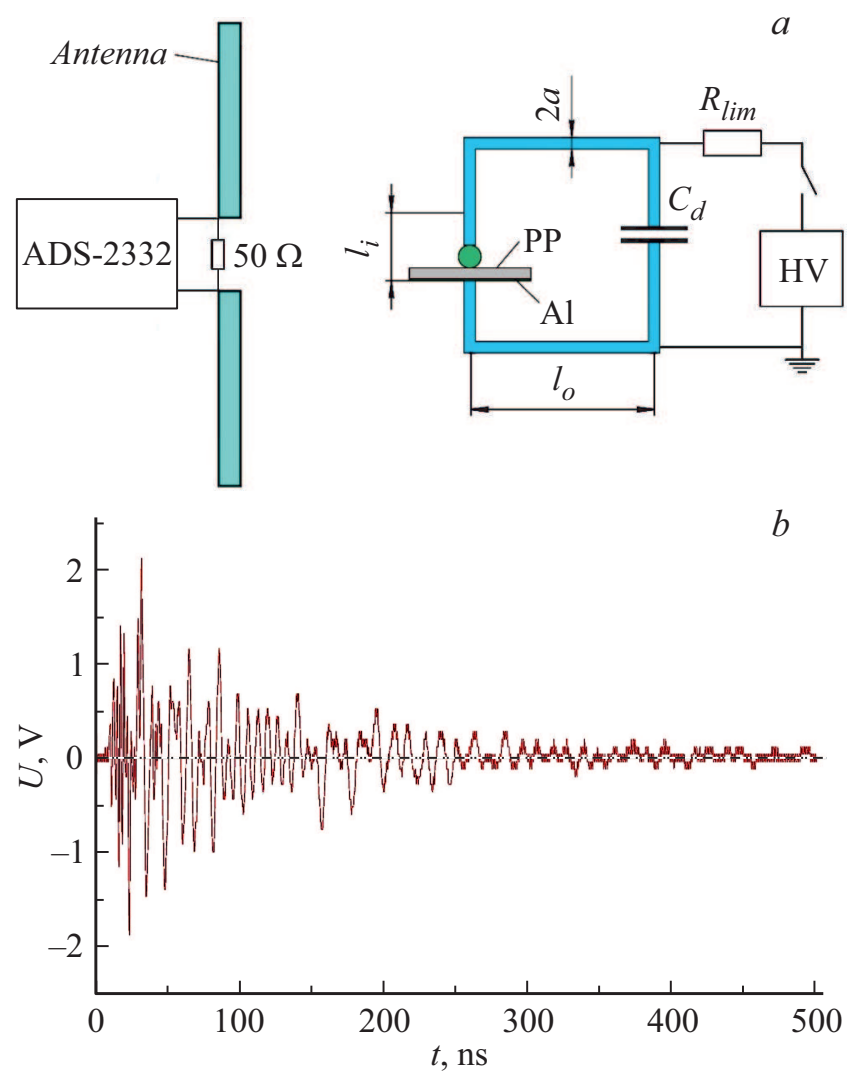

Рис. 1. $a-$ схема измерительной установки. $b-$ осциллограмма регистрируемого радиоимпульса при пробое пленки РР. Пробивное напряжение $U_{b r}=2800 \mathrm{~V}$. 

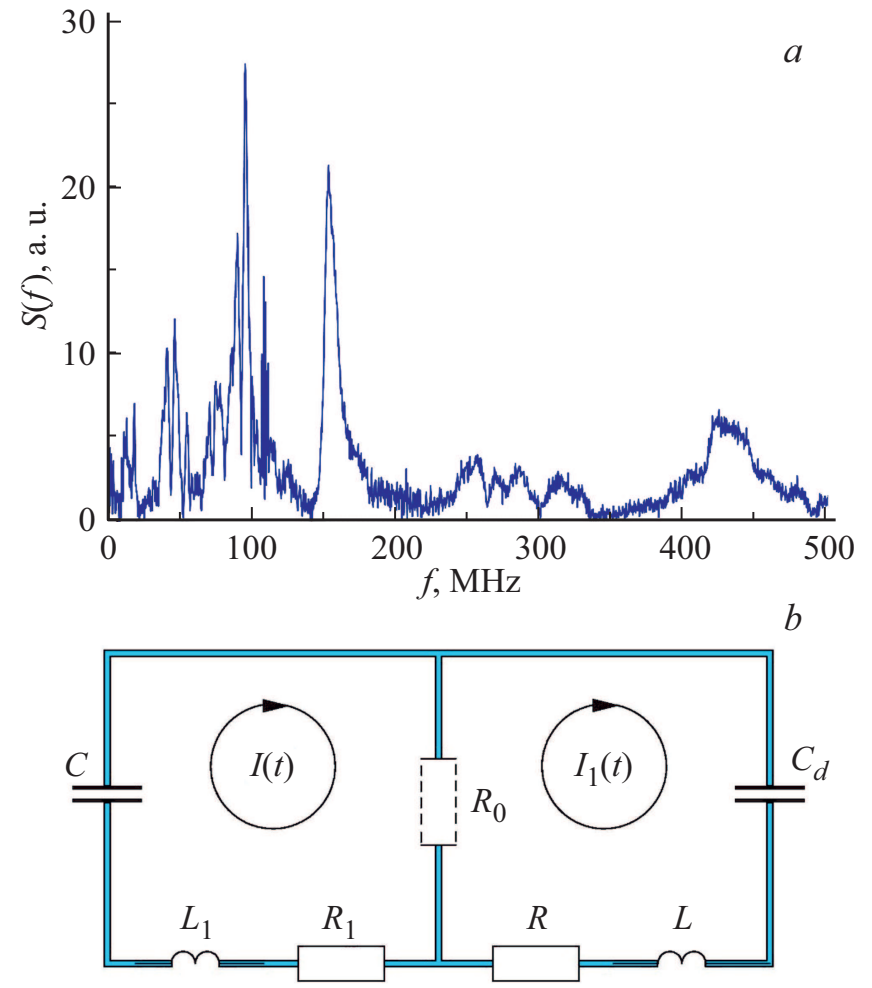

Рис. 2. $a-$ спектр приведенного на рис. $1, b$ радиоимпульса. $b-$ эквивалентная электрическая схема установки.

трубки. Нижний плоский торец провода рамки был прижат к слою Al. Таким образом, слой $\mathrm{Al}$ обеспечивал плотный контакт измерительной цепи с поверхностью полимера. Центр шарового электрода располагался на геометрической оси провода рамки. Все электрические испытания проводились в среде конденсаторного масла, что исключало возникновение краевых и поверхностных разрядов. Параллельно исследуемому образцу подключался конденсатор $C_{d}$, емкость которого составляла 56 pF. Высокое напряжение (HV) подавалось на исследуемый образец через ограничивающий резистор $R_{\text {lim }}$ сопротивлением $10^{11} \Omega$. Среднее значение пробивного напряжения $U_{b r}$ составило $2700 \pm 100 \mathrm{~V}$. В отличие от предыдущих схем измерений здесь измерительное сопротивление отсутствует, т.е. равно нулю. В месте пробоя в пленке возникал сквозной канал (канал пробоя) диаметром около $10 \mu \mathrm{m}$, вокруг которого слой $\mathrm{Al}$ испарялся. Диаметр деметаллизированной области составлял около $100 \mu \mathrm{m}$.

Для регистрации радиоизлучения без искажений необходимо использовать приемную антенну, согласованную со спектром излучения конкретной экспериментальной установки. Расчет параметров антенны был сделан на основе данных о спектре колебаний измерительной цепи. В работе [2] с использованием измерительного сопротивления установлено, что частота колебаний тока находится в диапазоне 90-200 MHz. Поэтому приемная антенна представляла собой вертикальный симметрич- ный вибратор диаметром $70 \mathrm{~mm}$ с длиной плеча $560 \mathrm{~mm}$ (резонансная частота $134 \mathrm{MHz}$ ). Антенна работала в апериодическом режиме и подключалась к запоминающему осциллографу ADS-2332 коасиальным кабелем длиной $1 \mathrm{~m}$, зашунтированным с двух концов резисторами $50 \Omega$ (рис. $1, a)$. Это позволило регистрировать радиоволны в диапазоне частот 50-500 MHz.

При электрическом пробое пленки РP были зарегистрированы радиоимпульсы длительностью около $400 \mathrm{~ns}$ и амплитудой до $2 \mathrm{~V}$. Максимальная амплитуда импульса зависела от величины $U_{b r}$. Типичная форма регистрируемого радиоимпульса представлена на рис $1, b$. Он имеет вид осциллирующего и затухающего по амплитуде сигнала, частота колебаний которого со временем изменяется. Сравнение его с осциллограммой сигнала, регистрируемого в электрической цепи при пробое полимерной пленки [1], показывает значительное сходство их формы и длительности. Это свидетельствует о правильном выборе приемной антенны. Спектр радиоимпульса представлен на рис 2,a. Анализ спектра отдельных частей осциллограммы показал, что высокочастотное излучение с центральной частотой $f_{H}=416 \mathrm{MHz}$ и низкочастотное с частотой $f_{L}=90 \mathrm{MHz}$ наблюдаются в начальной части осциллограммы в течение приблизительно $80 \mathrm{~ns}$, так что эти колебания накладываются друг на друга. После затухания указанных колебаний появилось излучение с частотой $f_{M}=147 \mathrm{MHz}$, длительность которого составляет около $50 \mathrm{~ns}$. Далее опять возникло излучение на частоте $90 \mathrm{MHz}$, из которого сформирована завершающая часть радиоимпульса.

В отличие от предыдущих измерений при пробое обнаружены колебания с относительно высокой частотой, существующие одновременно с низкочастотными колебаниями в передней части осциллограммы радиоимпульса. Для выявления связи сопротивления канала пробоя с характеристиками колебаний в [2] предложена эквивалентная электрическая схема (ЭС). Чтобы объяснить излучение на частотах $400-500 \mathrm{MHz}$, необходимо эквивалентную ЭС, рассмотренную в [2], дополнить высокочастотным контуром. Из общих соображений следует, что при пробое тонкого полимерного образца $L C$-контур с резонансной частотой $416 \mathrm{MHz}$ должен иметь индуктивность, существенно меньшую индуктивности всей установки, имеющей форму квадратной рамки (рис. $1, a)$. По нашему мнению, этот контур образован емкостью и индуктивностью электродов измерительной ячейки и проводников, прилегающих непосредственно к электродам имерительной ячейки. Этот же контур будет являться эквивалентным контуром высокочастотного излучающего вибратора длиной $l_{i} \approx 15 \mathrm{~mm}$ (высота измерительной ячейки). В работах $[1,2]$ индуктивность электродов измерительной ячейки не учитывалась. Источником низкочастотных составляющих спектра радиоимпульса являются затухающие колебания в квадратной рамке.

Эквивалентную схему установки можно представить в виде, показанном на рис. $2, b$, где $C-$ емкость 
высокочастотного контура, $L_{1}$ - индуктивность высокочастотного контура, $R_{0}$ - сопротивление канала пробоя, $L$ - индуктивность квадратной рамки (рис. 1$), R$ и $R_{1}-$ активные сопротивления проводников, $I(t), I_{1}(t)-$ контурные токи. Качественно процесс возникновения колебаний можно представить следующим образом. При пробое за очень короткое время сопротивление образца изменяется от $R_{\text {inf }}$ до $R_{0}$, причем $R_{\text {inf }} \gg R_{0}$. При этом конденсаторы $C$ и $C_{d}$, заряженные до напряжения пробоя $U_{b r}$, разряжаются. Наличие индуктивностей и емкостей приводит к возникновению затухающих колебаний. Если $R_{0}$ мало, то ток $I(t)$ является наиболее высокочастотным, в то время как ток $I_{1}(t)$ является низкочастотным. Поэтому в процессе радиоизлучения должны наблюдаться одновременно и низкая, и высокая частоты. Когда $R_{0}$ велико, через него протекает пренебрежимо слабый ток. В ЭС остается один общий контур с промежуточной резонансной частотой. Если $R_{0}$ не очень велико и контуры не являются зеркально симметричными, то существуют колебания на двух близких промежуточных частотах.

В результате можно сделать вывод, что частота излучения радиоволн определяется сопротивлением канала пробоя. Таким образом, по частоте излучения можно судить о величине сопротивления канала пробоя. Для количественных оценок были рассчитаны резонансные частоты ЭС $f$, которые очень близки к частотам затухающих колебаний. Резонансные частоты при произвольном $R_{0}$ находились путем приравнивания к нулю мнимых частей импедансов контуров ЭС $Z$ (со стороны конденсатора $C_{d}$ ) и $Z_{1}$ (со стороны конденсатора $C$ ). В случае $R_{0}=0$ ЭС распадается на два независимых контура с резонансными частотами

$$
\begin{gathered}
f_{H}=\frac{1}{2 \pi} \sqrt{\frac{1}{L_{1} C}} \text { для } Z_{1}, \\
f_{L}=\frac{1}{2 \pi} \sqrt{\frac{1}{L C_{d}}} \text { для } Z .
\end{gathered}
$$

Когда $R_{0}=\infty$, ЭС превращается в последовательный контур с резонансной частотой

$$
f_{M}=\frac{1}{2 \pi} \sqrt{\frac{C+C_{d}}{C C_{d}\left(L+L_{1}\right)}} .
$$

Резонансные частоты, соответствующие крайним значениям сопротивления канала $\left(R_{0}=0, \infty\right)$, приравнивались к частотам спектральных составляющих излучения. Таким способом была сформирована система трех уравнений для нахождения реактивных параметров излучающей системы $C, L_{1}$ и $L$, необходимых для определения сопротивления канала пробоя. Полученные параметры $C, L_{1}$ и $L$ подставлялись в выражения для импедансов ЭС с целью нахождения резонансных частот уже при произвольном $R_{0}$. При решении этой задачи активные сопротивления $R$ и $R_{1}$ находились путем суммирования

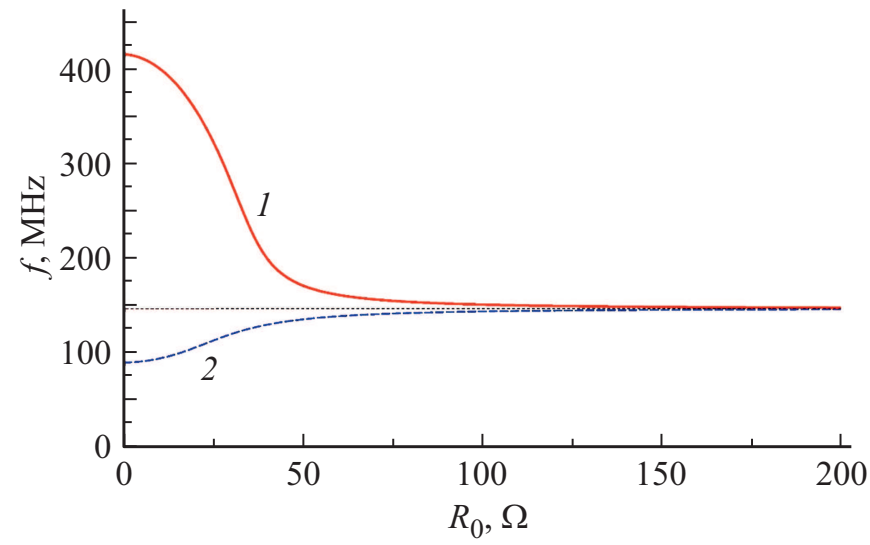

Рис. 3. Зависимость резонансной частоты от величины сопротивления канала пробоя в высокочастотном контуре (1) и низкочастотном контуре (2).

сопротивлений проводников с учетом глубины поверхностного эффекта и сопротивления излучения квадратной рамки и высокочастотного вибратора. Полученные алгебраические уравненния для $f$ не приводятся из-за большого объема. Эти уравнения решались численно при различном $R_{0}$. Далее строилась зависимость частот колебаний от сопротивления канала (рис. 3). Было найдено, что частотам $f_{L}=90 \mathrm{MHz}$ и $f_{H}=416 \mathrm{MHz}$ соответствует $R_{0} \sim 1 \Omega$, а частоте $f_{M}=147 \mathrm{MHz}$ отвечает $R_{0} \geqslant 100 \Omega$. Как видно из осциллограммы, сопротивление канала существенно изменяется во времени. Интересно, что излучение с частотой $f_{M}$, соответствующее относительно высокому сопротивлению канала, четко воспроизводится не в конце осциллограммы, а в средней ее части. Это значит, что на данном отрезке времени сопротивление канала резко возросло, а затем опять уменьшилось. Подобное поведение наблюдалось для всех испытанных образцов РР. Можно предположить, что в конце процесса пробоя сопротивление канала существенно возрастает, что должно сопровождаться появлением излучения на частоте $147 \mathrm{MHz}$. Скорее всего, так и происходит, но к этому времени энергия, запасенная в контуре, заметно рассеивается, и излучение на этой частоте становится ниже уровня шумов.

Таким образом, в работе зарегистрировано радиоизлучение, возникающее при пробое пленки РР. Основные спектральные пики наблюдаются на частотах 90, 147 и $416 \mathrm{MHz}$. Анализ электрических и радиотехнических характеристик экспериментальной установки дает основание полагать, что радиоизлучение обусловлено электрическими колебаниями тока пробоя в экспериментальной установке. Основная мощность выделяется в канале пробоя в результате протекания токов на частотах 416 и $90 \mathrm{MHz}$ в первые $80 \mathrm{~ns}$. При пробое пленки РP обнаружено немонотонное изменение сопротивления канала пробоя: резкое кратковременное увеличение сопротивления на фоне практически постоянного сопротивления, равного $\sim 1 \Omega$. Можно предполагать, что возрастание 
сопротивления вызвано кратковременным образованием плохопроводящего слоя на электродах измерительной ячейки. Целесообразно использовать радиоизлучение для исследования электрического пробоя, поскольку принятые сигналы хорошо воспроизводят колебания в реальной установке и этот метод более безопасен по сравнению с контактными измерениями. Использование радиоизлучения позволяет измерять токи одновременно во всех конутрах установки. По методике измерительных сопротивлений это сделать практически невозможно, что приводит к недостаточно полному представлению о протекающем процессе пробоя. В дальнейшем необходимо разработать методику, позволяющую определить влияние скорости изменения сопротивления канала пробоя на спектрально-временны́е характеристики регистрируемого радиоизлучения. Исследование закономерностей изменения сопротивления канала необходимо для детализациии физического механизма пробоя полимеров и разработки путей повышения электрической прочности изоляции.

Можно отметить, что некоторые параметры заключительной стадии электрического пробоя диэлектриков указывают на схожесть этого процесса с процессом электрического взрыва тонкой металлической проволочки [7]. По-видимому, радиоизлучение, которое должно возникать при электрическом взрыве проводников, также несет информацию об изменении сопротивления проводника во времени.

\section{Конфликт интересов}

Авторы заявляют, что у них нет конфликта интересов.

\section{Список литературы}

[1] Пахотин В.А., Закревский В.А., Сударь Н.Т. // ЖТФ. 2015. T 85. B. 8. C 40-45.

[2] Пахотин В.А., Сударь Н.T. // ПТЭ. 2019. № 3. С. 30-37. https://doi.org/10.1134/S0032816219020289

[3] Андреев Ю.А., Костыря И.Д., Кошелев В.И., Тарасенко В.Ф. // ЖТФ. 2006. Т. 76. В. 5. С. 105-111.

[4] Shibuya Y., Matsumoto S., Tanaka M., Muto H., Kaneda Y. // IEEE Trans. Dielectr. Electr. Insul. 2010. V. 17. N 3. P 862-871. https://doi.org/10.1109/TDEI.2010.5492260

[5] Zmarzly D., Nagi L., Borucki S., Boczar T. // Acta Phys. Pol. A. 2014. V. 125. N 6. P. 1377-1379. DOI:10.12693/APhysPolA.125.1377

[6] Suwarno H. // Int. J. Electr. Eng. Inform. 2016. V. 8. N 1. P. 147-163. DOI: 10.15676/ijeei.2016.8.1.11

[7] Орешкин В.И., Хищенко К.В., Левашов П.Р., Русских А.Г., Чайковский С.A. // ТВТ. 2012. Т. 50. № 5. С. 625-637. 